\title{
ORIGINAL ARTICLE \\ Digital piracy and the perception of price fairness: evidence from a field experiment
}

\section{Anna Kukla-Gryz ${ }^{1} \cdot$ Joanna Tyrowicz ${ }^{2,3,4}$ iD $\cdot$ Michał Krawczyk $^{1}$}

Received: 10 January 2018 / Accepted: 12 May 2020 / Published online: 12 June 2020

(c) The Author(s) 2020

\begin{abstract}
We study a relationship between perceived price fairness and digital piracy. In a large-scale field experiment on customers of a leading ebook store, we employ the Bayesian truth serum to elicit the information on acquiring books from unauthorized sources (often referred to as digital piracy). We provide empirical evidence in support of the conjecture that willingness to "pirate" is associated with having experienced subjective overpricing. We propose and verify the relevance of two mechanisms behind this link: reactance theory and moral cleansing/licensing. The results indicate that pricing policy perceived as fair may reduce the scope for digital piracy.
\end{abstract}

Keywords Unauthorized download · Digital piracy · Fair price · Online sales · Bayesian truth serum

Joanna Tyrowicz

j.tyrowicz@grape.org.pl

Anna Kukla-Gryz

akukla@wne.uw.edu.pl

Michał Krawczyk

mkrawczyk@wne.uw.edu.pl

1 Faculty of Economics, University of Warsaw, 44/50 Dluga, 00-241 Warsaw, Poland

2 Faculty of Management, University of Warsaw, 3 Szturmowa, 00-123 Warsaw, Poland

3 Group for Research in Applied Economics, Mazowiecka 11, 00-052 Warsaw, Poland

4 IZA, IZA, Schaumburg-Lippe-Straße 5-9, Bonn, Germany 


\section{Introduction}

The price of cultural goods has often been raised in public debate as one of the reasons why individuals resort to illicit downloading instead of legitimate purchases (often referred to as digital piracy ${ }^{1}$ ), see for example a report by AACU. ${ }^{2}$ Lysonski and Durvasula (2008) went as far as to claim that the so-called Generation Y is permissive of piracy because they consider themselves victims of music prices being artificially inflated by the industry. However, to the best of our knowledge, the very notion of "high price" is not academically defined and this relationship has not been verified in the earlier literature, see, e.g., meta-analyses by Liebowitz (2016) and Hardy et al. (2018). Moreover, a "high price" need not be viewed as an unfair or unjust price. Indeed, it appears that the literature has analyzed thoroughly the link between price and willingness to buy a cultural good (see, e.g., Hinduja 2003; Kwong et al. 2003; Al-Rafee and Cronan 2006; Higgins et al. 2008) with less attention devoted to the choices of alternative methods of acquisition. This paper reports results from a field experiment on the relationship between the experience of unfair pricing in the case of cultural goods and acquiring cultural goods from unauthorized sources.

Plausibly, when the price for a cultural good is viewed as unfairly high, it may reduce the sense of guilt associated with digital piracy. Such a pattern is theoretically founded in psychological reactance theory (Brehm and Brehm 1981). Alternatively, paying such a high price (and thus contributing to the creation of cultural goods) may provide a moral "license" for downloading from illicit sources in the future, or "cleanse" the perpetrator afterward (Carlsmith and Gross 1969; Tetlock et al. 2000). Naturally, heterogeneity is to be expected, with some individuals seeking moral justification for their actions and others being generally less concerned with the ethical aspects of downloading cultural content from unauthorized sources. Moreover, with moral licensing/cleansing, some individuals may report lower willingness to utilize unauthorized sources in the future and accept higher prices as penance for prior violations of copyright. In the light of this individual heterogeneity and given the ambiguous insights from theory, it is no longer obvious that the perception of price fairness correlates strongly with illicit downloading. It is our objective in this paper to put this mechanism to an empirical test. We formulate the following hypothesis:

Hypothesis Experience of unfair prices is positively associated with unauthorized downloading of cultural goods.

\footnotetext{
1 We refer to acquiring content from unauthorized sources rather than illegal downloading, because in many countries the actual acquisition is legal (only distribution being illegal and prosecuted). In the reminder of this paper, for the sake of brevity, we will interchangeably use the terms "downloading/ acquiring content from unauthorized sources" and "digital piracy," although we duly note the difference between the ethical and legal status of acquisition and distribution in many countries.

2 American Assembly of Columbia University: http://piracy.americanassembly.org/the-report/.
} 
We test this hypothesis in a field experiment, where we elicit engagement in digital piracy and experience of price unfairness with respect to the electronic books (ebooks). The literature is not clear on how to measure price fairness, so in the experiment we employ the alternative approaches. Since measuring the propensity to acquire content from unauthorized sources is a challenge due to potential underreporting, we employ an experimental method, Bayesian truth serum, utilized to incentivize truthful responses to sensitive questions (Prelec 2004). ${ }^{3}$

The intended contribution of our study is threefold. First, we analyze experimentally the link between perception of price fairness and digital piracy in the context of ebooks. To the best of our knowledge, this link has been conceptually postulated, but has not been so far put to an empirical test. Rather than stating generally that piracy exists because creative industries charge "high" prices, we investigate the price perception at individual level. Second, given the rich measurement of the price fairness, we can also compare if and to what extent the three different indicators exhibit differentiated relationship to downloading from illegitimate sources. Third, we exploit value statements to study which of the two theories-reactance theory versus cleansing/licensing theory - operates to determine the observed relationships.

The results speak in favor of our main hypothesis. Digital piracy rates prove to be rather substantial and the greater the experienced subjective unfairness in pricing of the same type of the cultural good, the higher the prevalence of downloading from unauthorized sources. The results prove robust across different specifications and measures of price unfairness. We also find that while general ethical concerns about digital piracy substantially reduce prevalence of downloading from unauthorized sources. Finally, we look at the moderators of the link between perceived price unfairness and (declared) piracy. These moderators are constructed to proxy for mechanisms postulated in the two main theories we consider: reactance theory and moral cleansing/licensing theory. They turn out to be insignificant, suggesting that it is a mix of mechanisms that drives the association.

Our findings have important implications for the pricing policies that are above and beyond an instantaneous decision on whether or not to buy a cultural good. ${ }^{4}$ Pricing experience from one type of cultural good may have direct spillovers to the propensity to purchase rather than "pirate" another type of cultural good. In fact, pricing policy is likely to affect general attitude toward the entire creative industry. Our results imply i.a. that attractive pricing should be widely communicated, possibly also to the groups of customers that are unlikely to purchase a product in question at the given time. Our result may also help to explain growing success of the recent models involving distribution of cultural goods via subscription plans rather than per-unit pricing, in a sense that the subscription plans may be viewed as fairer than prior per-unit pricing.

\footnotetext{
${ }^{3}$ Barrage and Lee (2010) discuss in detail the advantages of Bayesian truth serum, when compared to other methods of eliciting behavior.

${ }^{4}$ We see little reasons why our results should not hold for other cultural goods, but more research is needed to verify this conjecture.
} 


\subsection{Insights from the literature}

According to the psychological reactance theory (Brehm and Brehm 2013; see also Sonnabend 2016 for the context of physical goods), restricting access to a wanted object will lead to negative cognitions, affect and behavior. Thus, a person's desire to possess the object in question increases, even if it requires unusual, possibly illegitimate actions. Overly high perceived prices are one of the ways to restrict access (Sonnabend 2016). Such negative emotional reactions are reported in the literature on price perceptions. For example, Xia et al. (2004) suggest that the feeling of being treated unfairly (due to overly high prices) can evoke outrage and anger, usually directed toward the seller rather than toward the product involved in the transaction (see, e.g., Bougie et al. 2003; Zeelenberg and Pieters 2004). Many studies show that this may lead to reducing or substituting consumption of a given producer/seller. For example, in a classic study by Kahneman et al. (1986) most responders indicated they would be willing to exert extra effort to avoid purchasing in some stores when the price hike these stores implemented was perceived as unfair. Similar findings were reported by Thaler (1985) and Campbell (1999) among others.

However, abstaining from consumption is a different behavioral response than engaging in downloading from unauthorized sellers, i.e., pirating. We thus contribute to the literature by exploring a novel aspect of consumer reaction to pricing perceived as unfair. Notably, there are at least two important reasons why one should not automatically extrapolate the results from the past literature to the context of digital piracy. First, there is nothing morally questionable about the consumer's response in the previous studies: abstaining from consumption or switching to another seller are perfectly legitimate behaviors, whereas downloading from unauthorized sources raises some ethical concerns even among those who do it frequently (Tan 2002). Second, outraged customers - in line with the previous studies - may want to avoid having anything to do with the seller/product and perhaps support her competitors. Meanwhile, digital piracy involves consuming goods of exact same producers, only acquired without paying for.

Yet another reason for which consumers' negative reactions in markets for digital products may systematically differ from those typical for brick-and-mortar businesses studied before is the cost structure. Digital markets are characterized by high fixed cost and negligible variable cost. As Nunes et al. (2004) argued, amounts paid in excess of the variable cost are perceived as a gain to the seller, whereas failure to cover the seller's variable cost is perceived as a loss. The perceived harm to the seller may thus be greater if a consumer is failing to contribute to the variable cost (a loss) comparing to the failure to contribute to the fixed cost (a foregone gain).

Studies such as Darke and Dahl (2003) or Huppertz et al. (1978) construed fairness of pricing in the general context of equity theory (Adams 1963). In this approach, it is assumed that individuals seek fairness in social exchange. In particular, exchanges tend to be perceived as fair when the ratio of costs and benefits is the same for all participants. When individuals find themselves participating in relationships perceived to be inequitable, they try to take action to restore equity: buyers may justify digital piracy as a mean to reinstate equity. Such a pattern would also be 
consistent with the findings of Gupta et al. (2004) who observe that consumer's feeling of being "ripped off" might make (software) piracy a more acceptable option.

In addition, the context of the cultural goods is proven to differ substantially from general consumer choices. In the case of cultural goods, the price perception is not necessarily driven by concerns that are uniform across consumers: the subjective perception that the price is unfair is highly disperse for cultural goods and this dispersion cannot be explained away by the aesthetic perception of these cultural goods (Miyazaki et al. 2009). Thus, the link between digital piracy and price fairness may be driven by different mechanisms than the link between other consumer choices and price fairness.

Indeed, in the case of cultural goods, unfair price itself is a perplexing and problematic concept. First, the consumers are typically unaware of the costs involved in the production process. This is of paramount importance if consumers judge price fairness against some individualized priors rather than prevailing market levels. Second, in a popular debate, the consumers often declare support for the authors but not for the owners of the intellectual property rights, which implies for example in the case of music or books that the consumers may consider a given price level more fair if the authors received a higher fraction of this payment and copyright owners received a lower fraction of this payment. Third, consumption of many cultural goods may in principle be entirely free (legitimately): books may be borrowed from a local library, music is played over the radio; movies are screened on television; many museums have one free day per week, etc. The paid consumption involves aspects of cultural goods which is not only related to culture per se, but also to the consumers' preferred mode and timing of consumption. This implies that the price unfairness does not need to be related to the price per se, but to the value which consumers attribute to the timing and mode of consumption.

There are distinct features of cultural goods also when it comes to reactance. First, unlike with physical objects, acquiring the content from free, unauthorized sources is easy. Also, unlike the case of transgression related to physical objects, direct personal contract with the seller or distributor is generally not required, thus one avoids the tangible emotional costs of participation in an illegitimate activity. Given this relatively lower emotional and ethical cost of transgression, the experience of unfair pricing is plausibly more likely to lead consumers to seek alternative methods of acquisition (possibly involving free, unauthorized versions of the cultural good). Second, the cultural goods are purchased relatively often, e.g., compared to some conspicuous cultural goods (e.g., paintings, jewelry, designer furniture or home appliances). Therefore, the decision of whether a given price for a $\mathrm{CD}$ or a book at a given outlet is perceived as fair is taken relatively frequently and across many types of cultural good: movies, books, music, etc. Third, the degree of substitutability between legitimate and illegitimate cultural goods differs across the types of goods. Specifically, a downloaded movie is a poor substitute of viewing the same movie in a cinema theater night out with friends, for example. Meanwhile, the same downloaded movie is a suitable substitute for a DVD or pay-per-view movie to be watched at home. Thus, there is a broad array of mechanisms which may moderate the need to vent the discontent with price unfairness and the actual reaction of consumers. 
This complexity across domains links the insights from reactance theory with the notions of moral cleansing/moral licensing (see West and Zhong 2015; Blanken et al. 2015 for reviews). The mechanisms of moral licensing or moral cleansing may lead to a reciprocity of sorts, albeit via different channels than in the case of reactance theory. A good deed may make the decision maker feel more entitled to behave selfishly in the future (licensing), whereas a bad deed calls for a redemption (cleansing). In the context of acquiring cultural goods, having paid much compared to what could be considered a fair price in recent past is a generous act toward the publishers and authors, so that the customers may feel it is excusable to pirate some other cultural good for a change. Likewise, having downloaded a cultural good from an unauthorized source may trigger a feeling of guilt which is extinguished by purchasing the next one legally, even if it is perceived as overpriced.

To account for the complexity of the notion of price unfairness, we propose different ways to operationalize it, allowing us to test robustness of our observations. In all of them, we ask the participant to compare the last price paid for a book to her individual benchmark. In the most basic approach, the benchmark is what she says would be fair. Given the doubts as to the exact meaning of "unfair price" explored above, we pursue two alternative approaches. In the first one, the benchmark is the maximum willingness to pay (WTP), i.e., the highest amount that she would be willing to spend (Homburg et al. 2005). The WTP is often considered as a reservation price (Voelckner 2006), i.e., the upper bound on the range of fair prices. Finally, in our third approach, the benchmark is what the participant would voluntarily pay under a pay-what-you-want (PWYW) business model (see, e.g., Kim et al. 2009; Balan 2014). Being involved in the price setting process, consumers are understood to choose to pay a price that does not have a negative effect on their selfimage (Gneezy et al. 2012). It can be expected that prices in the PWYW mechanism will be lower than the WTP; PWYW contribution can be considered a logical lower bound of the range in which the fair price may be. These measures operationalize the notion of price fairness in our study.

\section{Methods}

We combined the insights from reactance theory and moral licensing/cleansing theory to theoretically underpin the link between the experience of price unfairness and downloading from unauthorized sources. We elicited three measures of price fairness, asking explicitly about the fair price, the willingness to pay and how much clients would have paid in the PWYW environment for a book they have acquired recently. We also asked the participants about the actual price they paid for this book and analyzed the discrepancy between any the three measures of fair price and the relevant price actually paid. Asking for the actual price allows us to adjust for the heterogeneity across customers, tastes and actual book titles.

Our study concerns the case of electronic books (ebooks), because this is one of the cultural goods where the purchased copy is a perfect substitute for a copy downloaded from unauthorized sources. Hence, consumers when making the choice do not have to optimize along other potentially relevant dimensions, such as quality 
of the copy and amenities associated with consumption. ${ }^{5}$ The fungibility of ebooks makes it also a credible case for why having experienced unfair pricing in this type of cultural goods may exhibit interactions with other types of cultural goods.

To study the behavior of ebook consumers, we invited to the study the customers of the largest online ebook store in Poland, Publio.pl. ${ }^{6}$ The clients of this ebook store receive a weekly e-mail newsletter about the current offers. The invitation to participate in the study was a part of one such newsletter, sent out on May 12, 2015. The study was implemented online and self-administered. It started with questions on the number of books read and bought over the three-month period prior to the study, as well as the criteria considered by the individuals when deciding about acquiring a book (see "Appendix 2"). The questions about prices and downloading from the unauthorized sources referred explicitly to the same period.

While the invitation clearly suggested that it was for an anonymous scientific study implemented at the University of Warsaw, responders may have been reluctant to answer the sensitive question about downloading from unauthorized sources truthfully. "Piracy" is an act that responders could potentially feel ashamed of; some of them may have also heard of distributors of movies and television series threatening to sue identifiable users of unauthorized sources. ${ }^{7}$ To address the issue, we have randomly assigned half of the sample (control group) to a standard questionnaire and the other half (treatment group) to the Bayesian truth serum variant of the questionnaire. The idea behind the BTS consists of linking the expected value of the rewards to the answers given by responders in such a way that they have material incentives to tell the truth. The subjects in the treatment group were told:

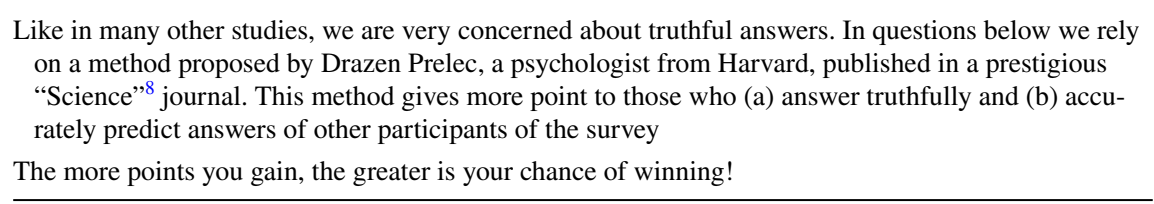

Implementation of point (b) above is simple, point (a) may be puzzling, given that the researcher is not able to verify truthfulness of any given response. However, Prelec (2004) formally showed that an honest answer will on average be "surprisingly popular," i.e., on average more people will choose it than expect it. This is because one's own behavior represents the bit of information that each responder has but others do not. An individual's posterior distribution as compared to others'

\footnotetext{
5 Admittedly, there can be differences in the user experience for downloading digital versions of the books. On the one hand, authorized distribution requires typically loging in, processing online payments, etc. (except for one global seller, nobody else is allowed to do one-click purchases, for example, except for one e-book reader, no other allows wireless purchase and download from inside the device, etc.). On the other hand, unauthorized distribution channels are frequently plagued with pop-up windows, the hazard of malware, etc. The balance of these trade-offs is highly individualized.

6 Due to the confidentiality agreement, we cannot disclose how many clients have received the e-mail.

7 Admittedly, these threats are somewhat dubious in the first place, as mere downloading is not illegal in Poland, most users may be unaware of this, see Filiciak et al. (2012).

8 A link to Prelec (2004) was provided to boost credibility.
} 
distributions will thus be shifted toward their true answer. Therefore, rewarding answers that are more often given than expected (as the BTS method does) induces truth-telling. ${ }^{9}$

Our implementation of BTS follows the standard adopted earlier in the literature. In both cases, we informed participants about the value (50 PLN 12.5 EUR each) of prizes to be won. While in the control group the invitation to the survey informed that gift certificates would be distributed randomly among the participants, in the BTS treatment group participants were informed that their chances of winning would depend on how truthful their answers were. We formulated our "sensitive" questions following closely the design of John et al. (2012). The first question concerned individual behavior: "Have you acquired an ebook or an audio-book from an unauthorized Internet source in the last three months?" (self-admission). Subjects were informed that when using the phrase unauthorized Internet source we referred to portals and P2P networks, which can be used to share files with other users (e.g., Chomikuj.pl, Bitshare.com). ${ }^{10}$ Following John et al. (2012) respondents were also asked to report the predicted admission rate, used in the BTS formulas to calculate each respondent's probability of winning.

In order to explore the potential effect of ethical consideration on self-admission, we included also a question about the motivations to abstain from downloading unauthorized content. This question was formulated indirectly, i.e., Why do you think some readers do not use unauthorized sources? Asking about a third party is frequently used when matter investigated is sensitive, while responders routinely use their own priors. Indeed, when guessing others' opinions, responders tend to use their own as a natural reference point, perhaps even more so than would be dictated by correct Bayesian inference, thereby giving rise to the "false consensus effect," see Ross et al. (1977). Had we instead asked respondents directly about their motivations to abstain from downloading unauthorized content, they could have had a tendency to give untruthful answers, seeking to present themselves in the best possible light.

Finally, we asked about motivations for not admitting to downloading files from unauthorized sources. We then inquired about the price of an actual cultural good purchased recently and the corresponding fair, maximum and PWYW price. We asked respondents to report the price of their most recently purchased fiction book. Having established this particular item to anchor the price valuation, we followed by eliciting the fair, maximum and PWYW prices. We asked explicitly, on the same screen:

\footnotetext{
9 Prelec's method has been proven effective in a number of earlier studies. For example, John et al. (2012) successfully used it to incentivize social psychologist to admit to questionable research practices, while Weaver and Prelec (2013) demonstrated the BTS to yield significantly more honest responses in a general knowledge questionnaire than the control group even when coupled with a mechanism encouraging overreporting one's knowledge. The BTS has been utilized in studies of optimal incentives for inexpert human raters (Shaw et al. 2011), informing policy (Weiss 2009) as well as ex ante analysis of new drug adoption (Howie et al. 2011).
}

${ }^{10}$ Chomikuj.pl is the most popular file-sharing service in Poland, according to traffic use statistics. 
- what is the maximum price you would be willing to pay for this particular book?

- what price for this particular book would you consider fair?

- if that book was available for sale in a "pay-what-you-want" scheme, how much would you pay for it?

Since responders were already in the possession of the book, they were not likely to perceive the situation as a process of bargaining. However, it is plausible that some of the customers have already read the book and for this very reason their ex post valuation differed either way from the price they already paid.

Note that the resulting difference between the reported maximum price and the actual price paid is a direct measure of the important economic notion of consumer surplus (although we actually use a difference in logarithms). For the other two measures - fair price and PWYW-the divergence between the price paid and the reported price are not directly interpretable in the light of microeconomic theory. Yet, in the case of the fair price, it can be identified as the extent to which the client has felt abused, as suggested by Hill (2007) and Brehm and Brehm (2013). For the PWYW, this is the potential scope for rendering all cultural goods purchase legitimate in a sense that if an ideal fair price for a given item is in excess of the current market price, customers may be incited to purchase now or in the future. A client who originally purchased from unauthorized source (e.g., file hosting services which distribute content for the price of transfer) is more likely to seek a discount price within authorized sources in the future.

The survey followed with some questions on brand recognition and reading habits as requested by Publio.pl online bookstore. Unlike the key survey questions explored in this study, these were not obligatory. The survey was concluded with demographics, such as gender, age, household size, residence and self-evaluated income status.

We used the survey questions to construct measures corresponding to the theoretical mechanisms discussed earlier. First, we constructed an index of high ethical concerns about piracy, based on questions C1, C2 and D1 of the survey, see "Appendix 2." "To facilitate interpretation of this variable, in particular the interpretation of its interaction with the measure of price fairness, we converted the continuous factor to a binary variable taking the value of 1 if individual scored above median and 0 otherwise. We label this variable "Piracy is an issue" for brevity.

Second, we constructed a variable to delineate the participants with principled (self-reported) motivations as opposed to those mainly driven by self-interest.

\footnotetext{
11 Specifically, we run a factor analysis of the variables collected in parts C1, C2 and D1 of the survey. One factor explained more than $40 \%$ of variability in the 34 variables considered, whereas other factors could be disregarded in the light of their low eigenvalues. This main factor showed very high, negative loadings for items such as "A. If services like these exist, they cannot be illegal," "B. Placing limitations on how people can share books with strangers constrains personal freedom" or " $\mathrm{C}$. There is nothing inappropriate about downloading books that cannot be purchased otherwise" and very high positive loadings for items such as "K. Services such as those earn profits at the expense of authors and publishers." "L. Distributing copyrighted content through services such as these is theft and those services are equally responsible for this crime" and "M. Services such as these will eventually reduce the influx of new books, because publishers will not be able to pay the authors.", which justifies our interpretation.
} 
Notably, sections $\mathrm{C} 1, \mathrm{C} 2$ forced the participants to prioritize their beliefs about the world (only three possible explanations could be chosen) and sections A1 and D1 explicitly asked the participants if they agreed or disagreed with statements about the nature of unauthorized downloading and sharing. We classify a participant as principled (a dummy variable takes on the value of 1) if the participant was concerned about rewards going to the artists, providing incentives for the artists and when the respondent explicitly stated that people do not download from the unauthorized sources when they consider that inappropriate (section C1 and C2). Note that these statements were made about the world in general; thus, the participants were not forced to describe their own behavior per se. We relied on directly expressed opinions of the participants setting the principled dummy to 1 also when the participant agreed or strongly agreed with the following statements: unauthorized sources are at the expense of the authors, unauthorized sharing is like theft, unauthorized sharing kills creativity of the authors (section D1). Finally, respondents also shared their opinions before the treatment assignment and before finding out the key survey questions in section A1. We set principled dummy to 1 if respondents report as important that the rewards should go to the authors, and that the law should be obeyed.

While the "Piracy is an issue" dummy is based on factor analysis of all the available variables, "Principled" dummy follows our selection of which variables should have meaningful link to reactance theory and moral licensing/cleansing. Based on reactance theory, we hypothesize that scoring high on the factor variable described above should be associated with attenuation of the experience of unfairly high prices, thus yielding a lower prevalence of (self-reported) piracy behavior. Indeed, whenever piracy is not considered a serious ethical issue, frustration associated with unfairly high prices may easily lead to retaliation and more frequent acquiring content from unauthorized sources.

Finally, using the available information, we also develop a tentative proxy for reactance per se. Namely, the respondents were asked to provide their views on the strongly disagree-strongly agree scale to two statements concerning the nature of copyright (section D1). These two items are "B. Placing limitations on how people can share books with strangers constrains personal freedom" and "E. Unclear or incorrect laws, such as the regulation on file-sharing through such services, may be ignored." These two items refer to general views about the world, but stating that one definitely agrees with both of them gives a strong statement on overall about the perception of copyright. In line with reactance theory, if one strongly rejects a legal norm, one is more likely to be in violation.

The three indicators that we propose have low cross-correlations (below the absolute value of 0.3 in each case). They also start from different methodological premises: a data-driven discretized factor variable, a value-based ad hoc measure and a views based ad hoc measure. Despite the differences, they are designed with the intention to verify the validity of the reactance theory in the context of unfair pricing of cultural goods and digital piracy thereof. 


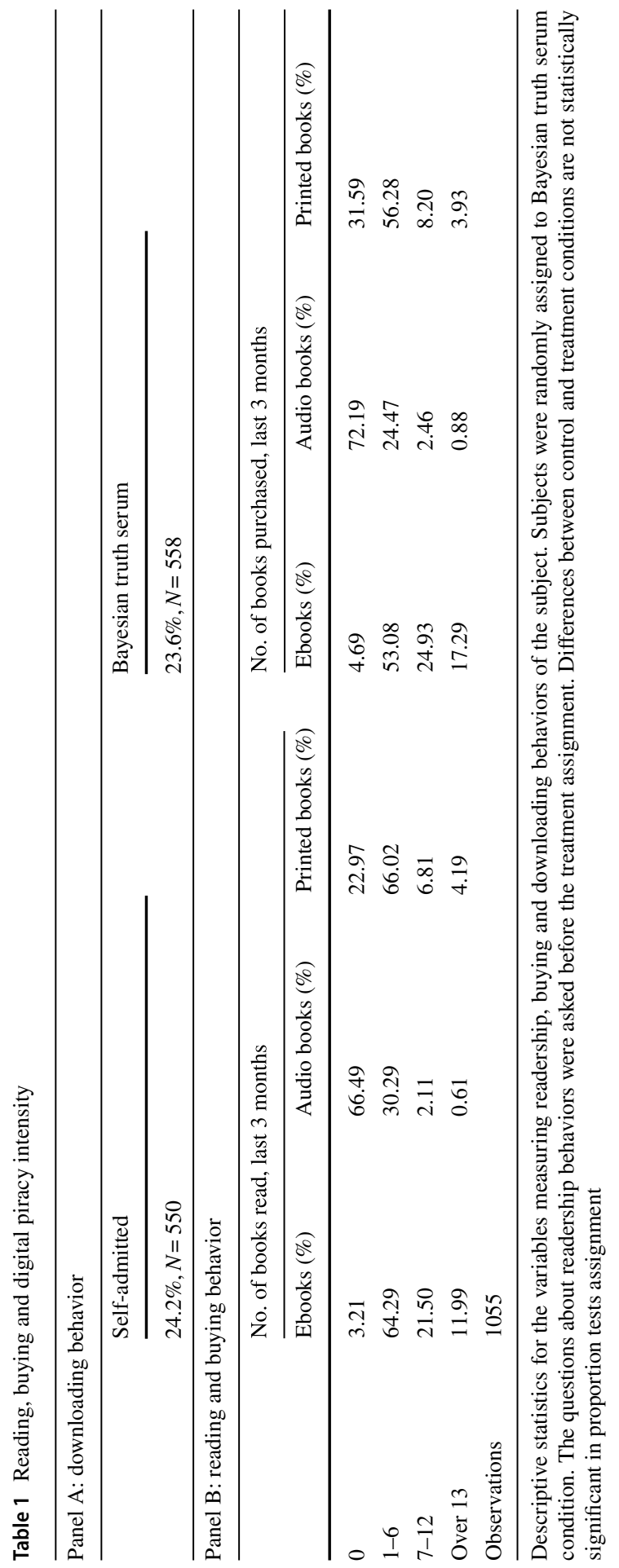




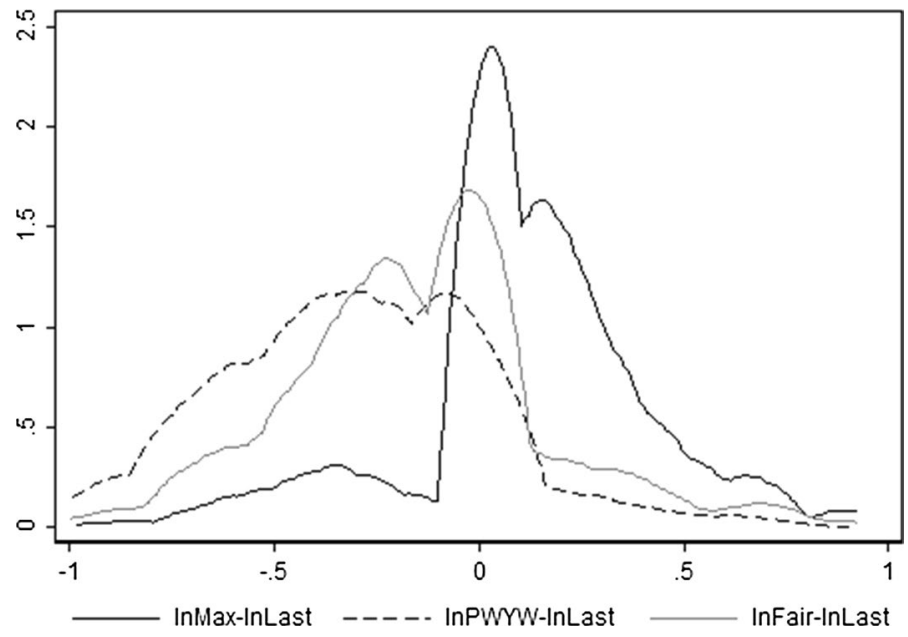

Fig. 1 Kernel density estimates for three measures of prices fairness

\subsection{Descriptive statistics}

We collected responses from 1257 customers, with 1055 complete surveys. The average age of the respondents was 42 years (consistent with average in population), with a good gender balance (51.3\% women). Majority of the subjects were frequent readers and buyers of ebooks (see Table 1). This is very encouraging in a sense that the sample of participants is competent in the topic at hand, since they actually make purchase and acquisition decisions on a regular basis. ${ }^{12}$ As for self-reported downloading, we find the prevalence of unauthorized downloading of approximately $24 \%$. The prevalence in the population of Publio.pl clients appears lower than reported in general for Polish Internet users. ${ }^{13}$ The fact that the self-admission rates do not differ between the incentivized and non-incentivized groups suggests yet another interesting phenomenon: as earlier literature provides convincing evidence that BTS is effective in eliciting truthful responses, this null results suggests that subjects did not actually think truthful declaring self-reported piracy was risky or shameful in the first place. Following the theoretical predictions, it should weaken the potential link between digital piracy and perceived price fairness.

For the price fairness measures, we compute the differences between the actual price paid and the three used measures of value to the subjects. We take the logarithms before we compute differences which implies these are effectively ratios in

\footnotetext{
12 The sample is clearly not representative of the entire population on this dimension-as many as $60 \%$ of adult Poles have not read a single book in a year (Korys et al. 2015).

13 For example, Filiciak et al. (2012) argue - based also on self-reported statistics - that on average $60 \%$ of Internet users are involved in downloading files from unauthorized sources. However, we have only asked about downloading books. The participants of the survey could still be "digital pirates" for movies, TV series or music. Moreover, the figure could be lower because our responders had been registered Publio.pl customers, thereby demonstrating they were willing to pay copyright holders for books (and possibly other cultural goods).
} 
Table 2 Basic estimates for self-admission rates

\begin{tabular}{|c|c|c|c|c|c|c|}
\hline \multirow[t]{2}{*}{ Self-admission } & \multicolumn{3}{|c|}{ All responders } & \multicolumn{3}{|l|}{ BTS only } \\
\hline & $\ln ($ fair/last $)$ & $\ln (\max /$ last $)$ & $\begin{array}{l}\ln (\mathrm{PWYW} / \\
\text { last) }\end{array}$ & $\ln ($ fair/last) & $\ln (\max /$ last $)$ & $\ln (\mathrm{PWYW} / \mathrm{last})$ \\
\hline $\begin{array}{l}\text { Price unfair- } \\
\text { ness }\end{array}$ & $\begin{array}{l}-0.127 * * * \\
(0.038)\end{array}$ & $\begin{array}{l}-0.163 * * * \\
(0.040)\end{array}$ & $\begin{array}{l}-0.076^{* * *} \\
(0.026)\end{array}$ & $\begin{array}{l}-0.133^{* *} \\
(0.054)\end{array}$ & $\begin{array}{l}-0.198 * * * \\
(0.058)\end{array}$ & $\begin{array}{l}-0.104 * * * \\
(0.036)\end{array}$ \\
\hline No of obs. & 972 & 981 & 979 & 478 & 484 & 482 \\
\hline
\end{tabular}

Demographic characteristics and income status included (not reported), price indicators measured as logarithm of a difference between a given type of valuation and the price reported as last paid, standard errors in parentheses, $* * * p<0.01$. $* * p<.05$. The number of observations in Table 2 is lower than in Table 1, because not all subjects responded to the control questions (age, gender, household size and income status) and to the price-related questions

percent between the value and the actual price paid. Figure 1 displays the three distributions. A non-negligible fraction reported negative consumer surplus. This could be related to the post-consumption re-evaluation of the book. On the other hand, $40 \%$ would seemingly still buy the book even if the price was $25 \%$ higher than the actual price paid, suggesting that the market prices are actually below WTP. Not surprisingly, the values for fair price and PWYW are much lower, the mode of the difference between fair and actual price is zero.

\section{Results}

In order to test the main hypothesis of this study, we formulate a probit model, where the dependent variable is a dummy taking the value of 1 if an individual reported downloading ebooks from unauthorized sources. The key independent variable is the measure of price unfairness. The additional independent variables in this model include the demographics controls and self-reported income status (in the "Appendices," we additionally report specifications where value statements are included explicitly). We construct a model for each of the price indicators, i.e., the difference of the logarithms of a given type of valuation and the actual price paid (see Table 2). We find negative and significant coefficients for price unfairness: higher gap between the (measures of) fair price and recent price experience is associated with higher prevalence of digital piracy. As expected, the coefficients differ between the definitions of price unfairness due to the nature of measurement. Note that these differences do not reflect the strength of the correlation, rather the expected and natural ranking of prices: PWYW price is on average lower than fair price, which is below the maximum acceptable price.

It is likely that individuals who acquire content from unauthorized sources (i.e., for free) have habitually lower fair, PWYW and maximum price valuations; hence, we cannot interpret these correlations as causal. To shed light on the possible mechanisms behind the link between the unfairness of prices and willingness to commit piracy, we looked at the responders' stated opinions about unauthorized sources. We used the measures discussed earlier: concerns about piracy as such (a factor variable turned into a dummy variable, taking on value 1 for individuals with a high score) 


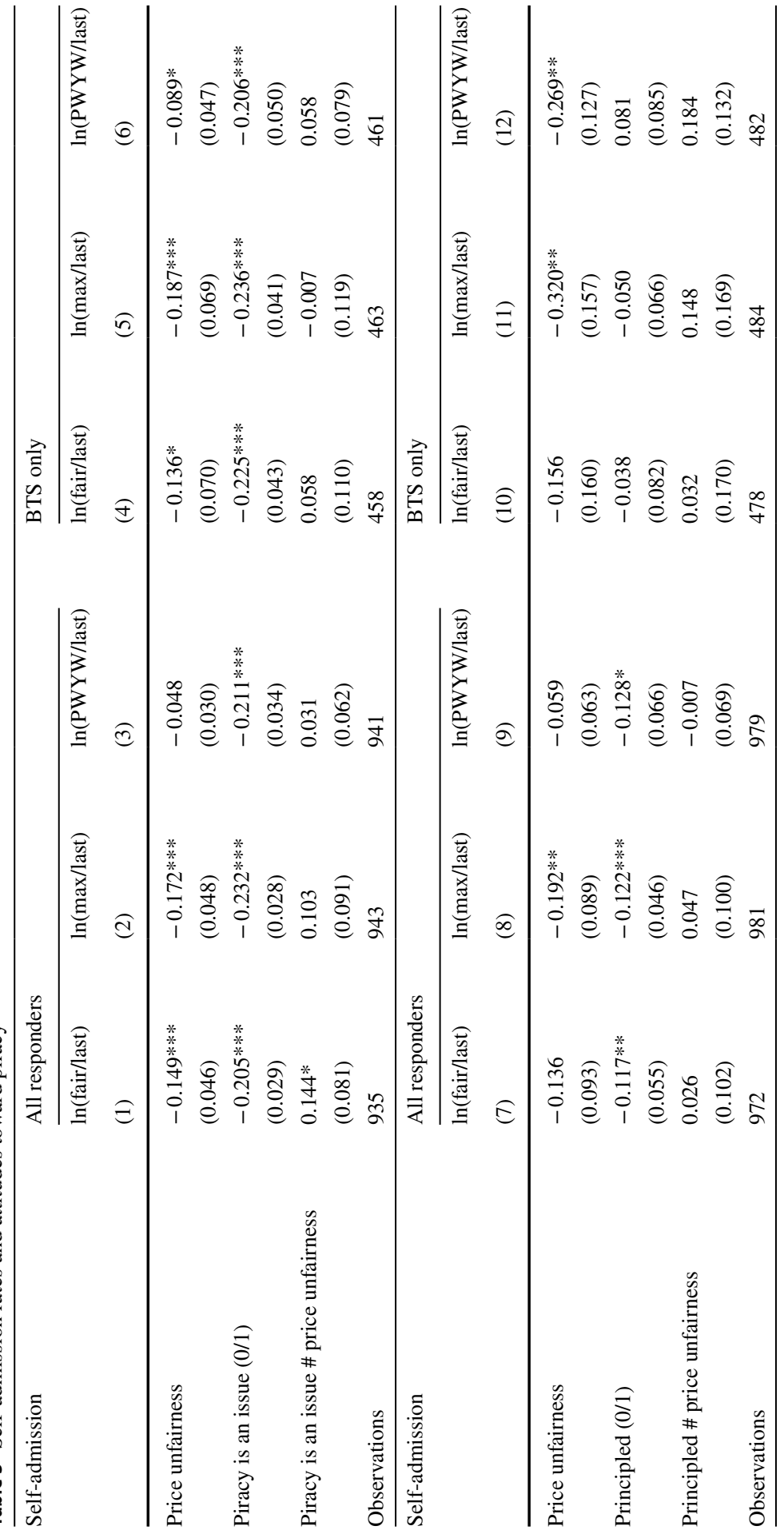




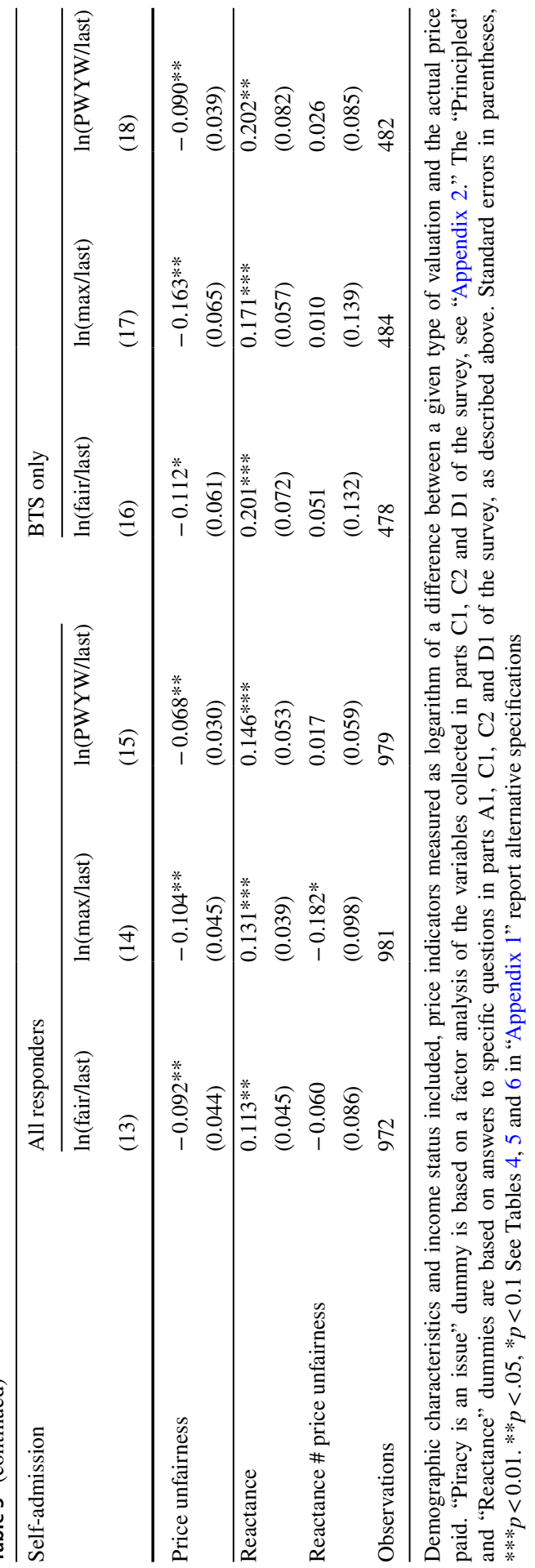


and principled motivations (constructed based on answers to some of the value questions). One should expect that these variables moderate the strength of the relationship between price unfairness and digital piracy. Table 3 reports the key findings (full set of estimates and numerous robustness checks across specifications are provided in Tables 4, 5 and 6 in "Appendix 1"). In all specifications, the coefficient on price unfairness is statistically equivalent to the estimates reported in Table 2. We find strong own effects of the "piracy is an issue" dummy. Self-reported piracy is lower among individuals who declare principled motivations, but that pattern is not confirmed in the incentivized BTS treatment. Given that the average piracy rates are similar for the BTS treatment and the control treatment, this result suggests that it is not overall prevalence, but rather individual characteristics that can be informative about the link between price unfairness and downloading from unauthorized sources.

Notably, however, the interaction terms are insignificant across specifications, measures of price unfairness as well as value-based measures of ethical views. Namely, both the reactance theory and the moral cleansing/licensing hypothesis predict that the individual stance will be a mediating factor, but we find no significant coefficients for the interaction terms. The interaction terms are systematically positive, but they are imprecisely estimated. For example, while being "principled" is associated with less (selfreported) piracy, as expected, here too the interaction term is estimated with systematically positive sign, but also relatively low precision. The positive sign would speak in favor of reactance theory, but lacking significance one cannot reject the hypothesis that there is no attenuation or amplification effects. Notably, asking about the third party may be insufficiently direct to gauge the size of the true effects of "principled" motivations. Overall, respondents views tend to be consistent with their actions, but these views do not inflate the original experience of price unfairness, nor do they reduce it.

We interpret weak confirmation of the moral licensing/cleansing mechanism as indicative that this channel is definitely present. Low precision of the estimation of interaction terms may stem from a variety of factors. The most apparent explanation is that there is some operation of the reactance theory: not strong enough to affect the sign of the estimated effects, but strong enough to account for large standard errors in our estimation. Another line of interpreting these results would focus on potential other channels to drive the link between (the experience of) price unfairness and piracy in the context of the digital cultural goods. The result may also be related to the selection into book consumption. Individuals purchasing books may be more conscientious than average, which would make channels such as moral licensing/cleansing operate to a weaker extent, even in the absence of mechanisms associated with reactance theory.

Tables 4, 5 and 6 in "Appendix 1" also report the gradients of self-reported piracy for age, gender and household size. We find that self-reported piracy is lower among older individuals. We find no gender differences. Individuals coming from larger households do not seem to be more likely to engage in self-reported piracy. Age gradient and lack of gender gradient are consistent with prior literature: our subjects are already familiar with technology enough to acquire digital content online, whereas prior literature on gender and age has been typically identifying differences in digital skills rather than differences in proclivity to engage in self-reported piracy (Phau et al. 2014). 


\section{Discussion and conclusions}

Our objective in this study was to provide evidence on the link between the experience of unfair pricing and engaging in online piracy. There are strong theoretical grounds as to why the two should be related, with possible spillovers between different cultural goods and consumption experiences. To pin down the identifiable scope of "unfairness" and relate it to online piracy, we developed an experimental study and administered it in an online survey among a large group of clients of the largest online ebook store in Poland. We employ Bayesian truth serum to incentivize reporting of the actual engagement in online piracy. We also constructed three measures of price fairness, a discrepancy between the actual price paid and either the maximum price one would pay, the price one would consider fair, or the price one would pay in a pay-what-you-want environment. While these measures differ in interpretation, they also prove to differ in value, but not in relationship to online piracy-we find strong and robust evidence that the experience of overpaying is associated with higher frequency of digital piracy. We are not arguing that this relationship is causal, rather that the results confirm a robust and theoretically plausible correlation.

Admittedly, it is a limitation of our study (again, ubiquitous for surveys) that we have to rely on self-reports rather than actually observed behavior. The fact that selfreports are unaffected also when the BTS mechanism providing strong incentives to tell the truth is implemented suggests that responders are not strongly tempted to tell lies instead. Naturally, BTS mechanism could provide insufficiently strong incentives to the responders. Even if some "pirates" did not admit to unauthorized acquisition, it appears that those driven by relatively principled motivations abstain from downloading even if the market prices for digital goods are viewed as unfair.

Another concern about our approach is that books are par excellence experience goods: their value can only be fully assessed after they are read. It may thus be that numbers reported as maximum willingness to pay or intended contributions under pay-what-you-want to some extent reflect ex post evaluations rather than those from the moment of purchase. This possibility does not invalidate our findings, though. Responders may still discover (albeit only ex post) that they have been overcharged and react accordingly.

Overall, our findings confirm the notion that acquiring unauthorized products is related to the perception of price fairness, not necessarily the level of prices themselves. Price perceptions may be partly shaped by the actions of the creative industries. One such example is the rapid growth of distributing content in the subscription plan model rather than per-item pricing. Thus, while "competing with free" may seem a lost cause, a pricing policy perceived as fair is likely to reduce the scope for ethical excuse among potential "pirates," converting them into paying customers.

Acknowledgements Authors express gratitude to an online e-book store Publio.pl for allowing to perform this study on clients. Earlier versions of this paper have received valuable comments from Alek Tarkowski, Jarosław Lipszyc, Mirosław Sroka. Peter Szewczyk and Katarzyna Zagórska provided wonderful research assistance. This study was previously presented at seminars of GRAPE, SGH, UW as well as CopyCamp seminars, where we obtained many interesting interpretations and insights and for which we are thankful to the participants. Anna Kukla-Gryz gratefully acknowledges the support of National Science Centre, Grant 2014/14/E/HS4/00389. Joanna Tyrowicz and Michał Krawczyk gratefully 
acknowledge the support of the National Science Centre, Grant 2011/01/D/HS4/03937. All opinions expressed are those of the authors and have not been endorsed by NSC.

Funding The research was funded by National Science Centre Grants 2014/14/E/HS4/00389 and 2011/01/D/HS4/03937.

\section{Compliance with ethical standards}

Conflict of interest Authors declare no conflict of interest.

Open Access This article is licensed under a Creative Commons Attribution 4.0 International License, which permits use, sharing, adaptation, distribution and reproduction in any medium or format, as long as you give appropriate credit to the original author(s) and the source, provide a link to the Creative Commons licence, and indicate if changes were made. The images or other third party material in this article are included in the article's Creative Commons licence, unless indicated otherwise in a credit line to the material. If material is not included in the article's Creative Commons licence and your intended use is not permitted by statutory regulation or exceeds the permitted use, you will need to obtain permission directly from the copyright holder. To view a copy of this licence, visit http://creativecommons.org/licen ses/by/4.0/.

\section{Appendix 1}

\section{Sample description}

See Figs. 2, 3, 4 and 5.

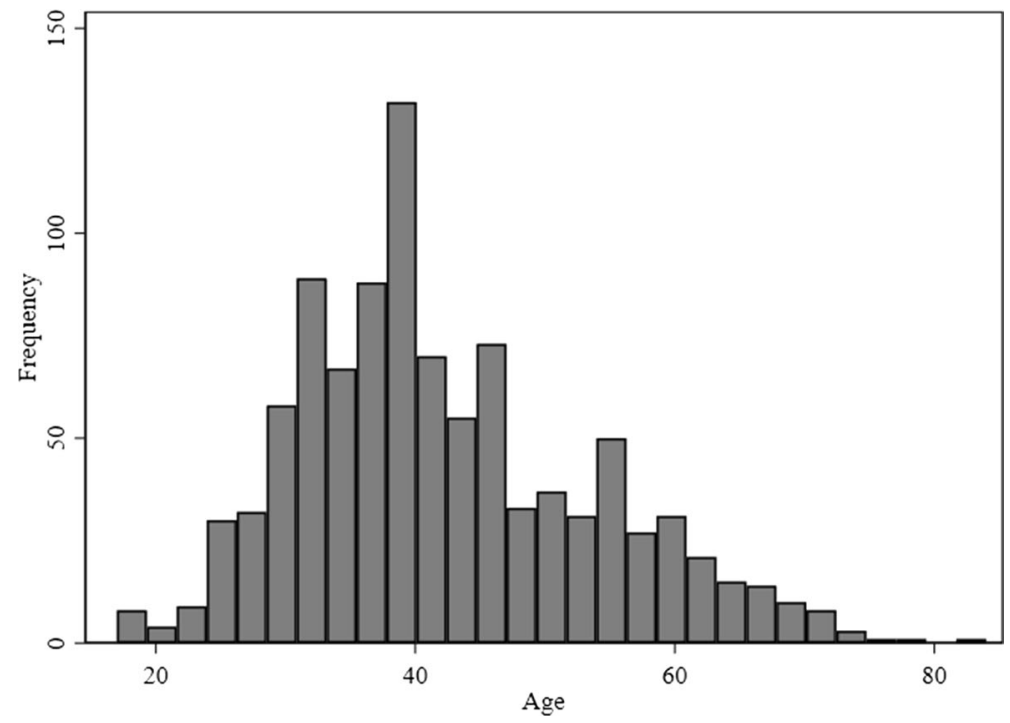

Fig. 2 Age distribution 


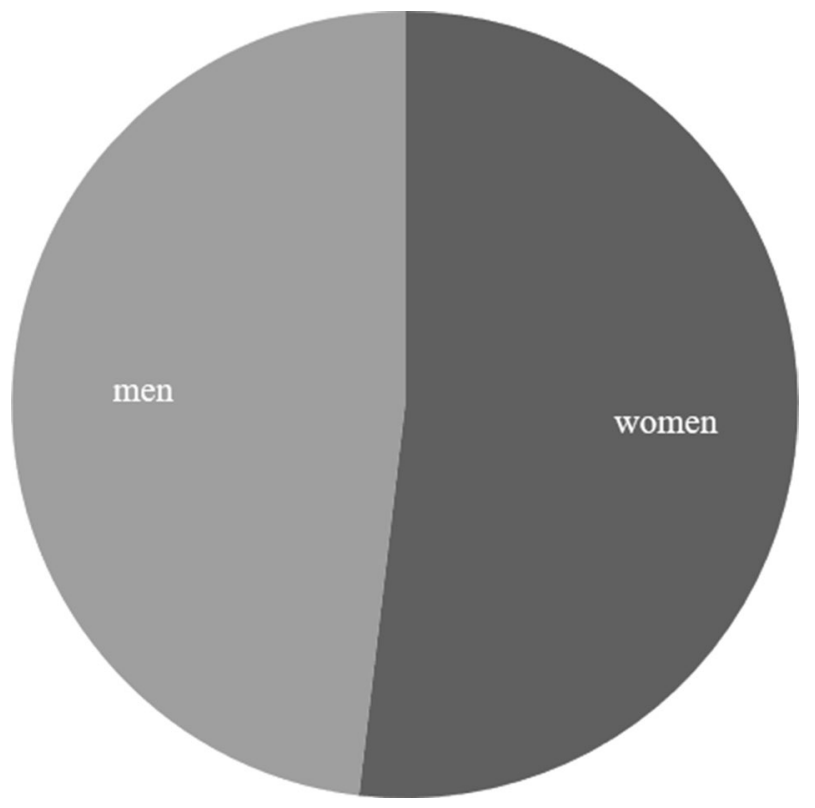

Fig. 3 Gender distribution

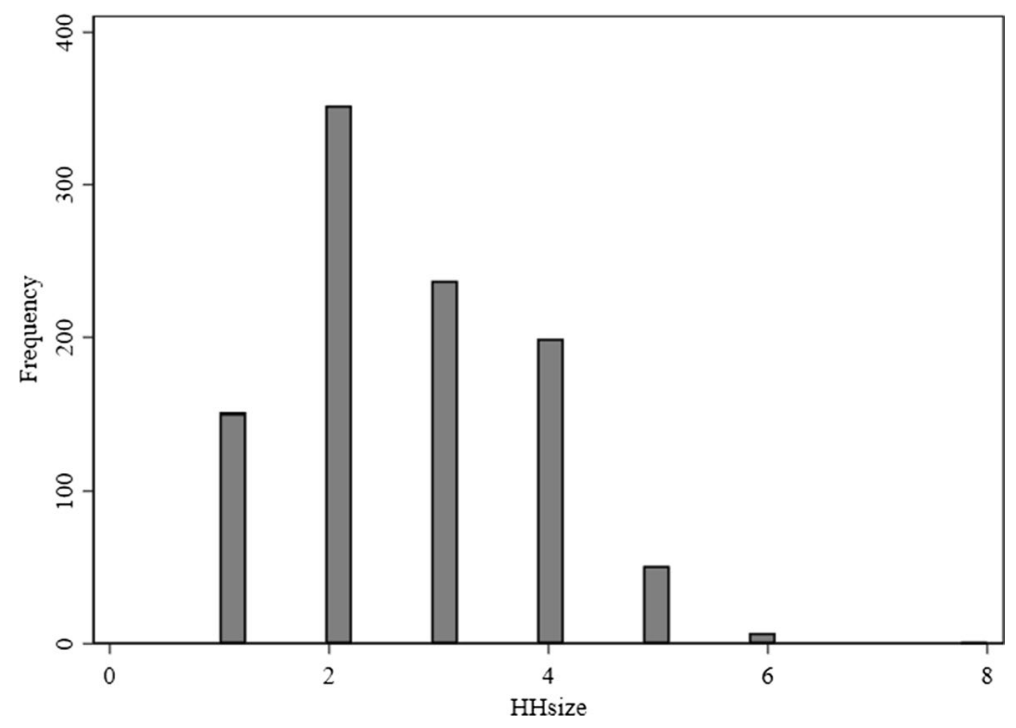

Fig. 4 Household size distribution 


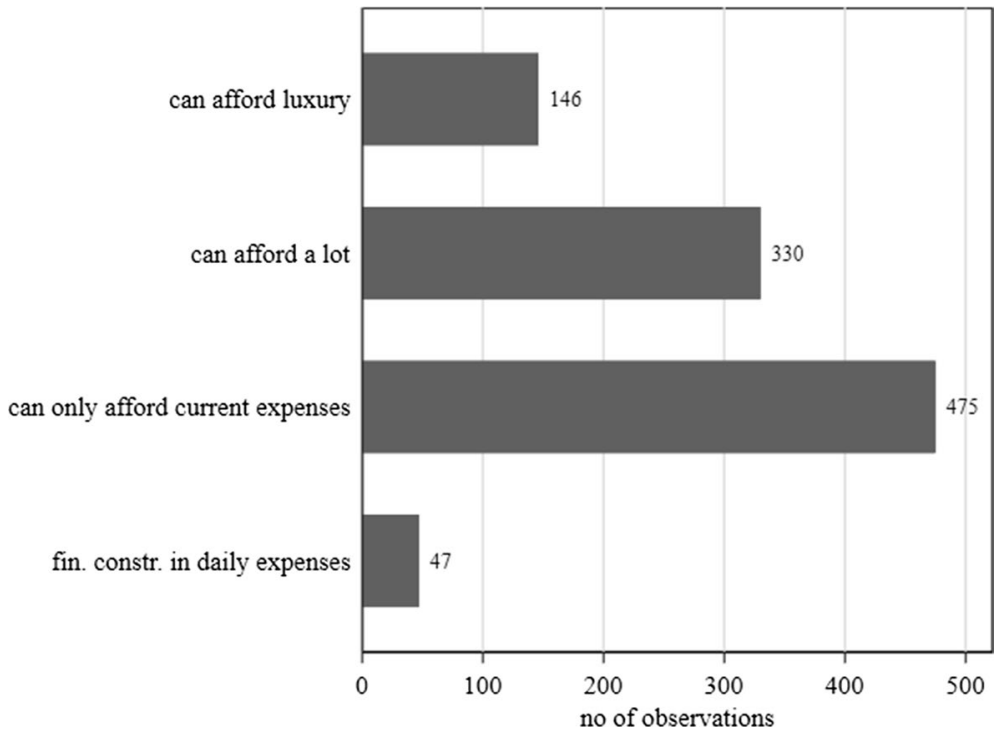

Fig. 5 Income situation

\section{Estimation results}

See Tables 4, 5 and 6. 
Table 4 Experience of high fair-to-actual price ratio and unauthorized downloading

\begin{tabular}{|c|c|c|c|c|c|}
\hline & (1) & (2) & (3) & (4) & (5) \\
\hline $\ln$ (fair/last paid) & $\begin{array}{l}-0.129 * * * \\
(0.045)\end{array}$ & $\begin{array}{l}-0.141^{* * * *} \\
(0.045)\end{array}$ & $\begin{array}{l}-0.125^{* * * *} \\
(0.046)\end{array}$ & $\begin{array}{l}-0.093 * * \\
(0.045)\end{array}$ & $\begin{array}{l}-0.130^{\text {**** }} \\
(0.046)\end{array}$ \\
\hline Piracy is an issue $(0 / 1)$ & $\begin{array}{l}-0.235^{* * *} \\
(0.028)\end{array}$ & $\begin{array}{l}-0.228 * * * \\
(0.028)\end{array}$ & $\begin{array}{l}-0.230 * * * \\
(0.029)\end{array}$ & $\begin{array}{l}-0.191 * * * \\
(0.030)\end{array}$ & $\begin{array}{l}-0.189 \text { *** } \\
(0.031)\end{array}$ \\
\hline Piracy is an issue \# $\ln$ (fair/last paid) & $\begin{array}{l}0.198 * * \\
(0.080)\end{array}$ & $\begin{array}{l}0.197 * * \\
(0.081)\end{array}$ & $\begin{array}{l}0.186^{* *} \\
(0.081)\end{array}$ & $\begin{array}{l}0.128 \\
(0.081)\end{array}$ & $\begin{array}{l}0.165^{* *} \\
(0.081)\end{array}$ \\
\hline \multicolumn{6}{|l|}{ Individual controls } \\
\hline Age & & $\begin{array}{l}-0.004^{* * * *} \\
(0.001)\end{array}$ & $\begin{array}{l}-0.005^{* * * *} \\
(0.001)\end{array}$ & $\begin{array}{l}-0.004^{* * * *} \\
(0.001)\end{array}$ & $\begin{array}{l}-0.004^{* * * *} \\
(0.001)\end{array}$ \\
\hline Male & & $\begin{array}{l}0.004 \\
(0.028)\end{array}$ & $\begin{array}{l}0.027 \\
(0.028)\end{array}$ & $\begin{array}{l}-0.024 \\
(0.028)\end{array}$ & $\begin{array}{l}0.005 \\
(0.028)\end{array}$ \\
\hline HHsize & & $\begin{array}{l}0.000 \\
(0.012)\end{array}$ & $\begin{array}{l}0.000 \\
(0.011)\end{array}$ & $\begin{array}{l}0.000 \\
(0.011)\end{array}$ & $\begin{array}{l}0.004 \\
(0.012)\end{array}$ \\
\hline Household financial status & & Yes & Yes & Yes & Yes \\
\hline Buying and reading intensity & & & Yes & & \\
\hline Criteria & & & & Yes & \\
\hline Why not using unauthorized sources & & & & & Yes \\
\hline Observations & 948 & 942 & 942 & 942 & 942 \\
\hline
\end{tabular}

Self-admission to download an ebook from unauthorized sources as dependent variable in all models ( 1 -admitted, 0 — not admitted). $* * * p<0.01,{ }^{* *} p<0.05$; standard errors in parentheses. To analyze relative rather than absolute discrepancy between the two, we use the difference between their natural logarithms $(\ln ($ fair $)-\ln ($ last $)=\ln ($ fair/last $)$. Household financial status identified with the use of the standard scale in household budget surveys (we can afford luxury, we can afford a lot, we can only afford current expenses, we cannot make the ends meet). Regressions with particular factors included in "Reading and Buying Intensity" model and "Criteria when acquiring a book" model and "Why Not Using Unauthorized Sources" model are available upon request. The following variables are included in "Reading and Buying Intensity": A1, A2, A3 and A4. The following variables are included in "Criteria when acquiring the book": A5. The following variables are included in "Why Not Using Unauthorized Sources": C2 
Table 5 Experience of high consumer surplus and unauthorized downloading

\begin{tabular}{llllll}
\hline & $(1)$ & $(2)$ & $(3)$ & $(4)$ & $(5)$ \\
\hline $\ln (\mathrm{max} /$ last paid) & $-0.138^{* * *}$ & $-0.160^{* * *}$ & $-0.155^{* * *}$ & $-0.144 * * *$ & $-0.162 * * *$ \\
& $(0.045)$ & $(0.047)$ & $(0.047)$ & $(0.046)$ & $(0.047)$ \\
Piracy is an issue (0/1) & $-0.269 * * *$ & $-0.263 * * *$ & $-0.259 * * *$ & $-0.209 * * *$ & $-0.219 * * *$ \\
& $(0.029)$ & $(0.029)$ & $(0.029)$ & $(0.031)$ & $(0.032)$ \\
Piracy is an issue \# ln(max/last paid) & 0.133 & 0.141 & 0.122 & 0.100 & 0.137 \\
& $(0.090)$ & $(0.091)$ & $(0.089)$ & $(0.092)$ & $(0.090)$ \\
Individual controls & & & & & \\
Age & & $-0.005 * * *$ & $-0.005 * * *$ & $-0.004 * * *$ & $-0.005 * * *$ \\
Male & & $(0.001)$ & $(0.001)$ & $(0.001)$ & $(0.001)$ \\
Household size & & 0.009 & 0.031 & -0.023 & 0.009 \\
Household financial status & & $(0.027)$ & $(0.027)$ & $(0.027)$ & $(0.027)$ \\
Buying and reading intensity & & -0.000 & 0.000 & 0.000 & 0.004 \\
Criteria & & $(0.011)$ & $(0.011)$ & $(0.011)$ & $(0.011)$ \\
Why not using unauthorized sources & & Yes & Yes & Yes & Yes \\
Observations & 956 & 949 & 949 & 949 & 949 \\
\hline Self-admission to dow & & & & Yes & Yes \\
\hline
\end{tabular}

Self-admission to download ebook from unauthorized sources as dependent variable in all models (1admitted, 0 - not admitted). $* * * p<0.01$; standard errors in parentheses. $\ln (\max )$ denotes self-reported maximum price acceptable for the respondent; $\ln$ (last paid) denotes the last reported price paid for the same ebook. To analyze relative rather than absolute discrepancy between the two, we use the difference between their natural logarithms. Household financial status identified with the use of the standard scale in household budget surveys (we can afford luxury, we can afford a lot, we can only afford current expenses, we cannot make the ends meet). Regressions with particular factors included in "Reading and Buying Intensity" model and "Criteria when acquiring a book" model and "Why Not Using Unauthorized Sources" model are available upon request. The following variables are included in "Reading and Buying Intensity": A1, A2, A3 and A4. The following variables are included in "Criteria when acquiring the book": A5. The following variables are included in "Why Not Using Unauthorized Sources": C2 
Table 6 PWYW-to-actual and unauthorized downloading

\begin{tabular}{llllll}
\hline & $(1)$ & $(2)$ & $(3)$ & $(4)$ & $(5)$ \\
\hline ln(PWYW/last paid) & $-0.059^{*}$ & $-0.053^{*}$ & -0.045 & -0.021 & -0.043 \\
& $(0.031)$ & $(0.030)$ & $(0.030)$ & $(0.030)$ & $(0.031)$ \\
Piracy is an issue (0/1) & $-0.225^{* * *}$ & $-0.222^{* * *}$ & $-0.225^{* * *}$ & $-0.193^{* * *}$ & $-0.183^{* * *}$ \\
& $(0.034)$ & $(0.034)$ & $(0.034)$ & $(0.035)$ & $(0.036)$ \\
Piracy is an issue \# ln(PWYW/last & 0.089 & 0.087 & 0.076 & 0.039 & 0.072 \\
paid) & $(0.062)$ & $(0.062)$ & $(0.062)$ & $(0.062)$ & $(0.063)$ \\
Individual controls & & & & & \\
Age & & $-0.004^{* * *}$ & $-0.004^{* * *}$ & $-0.003^{* * *}$ & $-0.004^{* * *}$ \\
& & $(0.001)$ & $(0.001)$ & $(0.001)$ & $(0.001)$ \\
Male & & 0.010 & 0.031 & -0.021 & 0.011 \\
& & $(0.027)$ & $(0.027)$ & $(0.028)$ & $(0.028)$ \\
Household size & & -0.001 & -0.001 & -0.000 & 0.003 \\
& & $(0.011)$ & $(0.011)$ & $(0.011)$ & $(0.011)$ \\
Household financial status & & Yes & Yes & Yes & Yes \\
Buying and reading intensity & & & Yes & & \\
Criteria & & & & Yes & \\
Why not using unauthorized sources & & 949 & 949 & 949 & 949 \\
Observations & 956 & 949 &
\end{tabular}

Self-admission to download ebook from unauthorized sources as dependent variable in all models (1admitted, 0 —not admitted). $* * * p<0.01, * * p<0.05$; standard errors in parentheses. Variable $\ln (\mathrm{PWYW})$ denotes the logarithm of the self-reported pay-what-you-want price of the respondent; $\ln$ (last paid) is a price actually paid for this ebook. To analyze relative rather than absolute discrepancy between the two, we use the difference between their natural logarithms. Household financial status identified with the use of the standard scale in household budget surveys (we can afford luxury, we can afford a lot, we can only afford current expenses, we cannot make the ends meet). Regressions with particular factors included in "Reading and Buying Intensity" model and "Criteria when acquiring a book" model and "Why Not Using Unauthorized Sources" model are available upon request. The following variables are included in "Reading and Buying Intensity": A1, A2, A3 and A4. The following variables are included in "Criteria when acquiring the book": A5. The following variables are included in "Why Not Using Unauthorized Sources": C2 


\title{
Appendix 2: The survey
}

\author{
Appendix B. The survey \\ I This is a translation, the survey was originally administered in Polish. The survey was administered on a population of customers of one \\ of the virtual bookstore Publio. The final part of the survey contained the proprietary questions of Publio. These proprietary questions are \\ not reported. The invitation to participate in the survey informed about the anonymous and scientific character of this study, mentioned that \\ the University of Warsaw was involved. It was also emphasized that an e-mail address will be requested to send winners the coupon. The \\ names of the screens reported below were not shown to the participants (they serve to delineate subsequent parts of the survey)./ \\ Hello! Welcome to our study on ebooks, audiobooks and printed books. All participants have a chance to receive a coupon of 50 PLN [ 12 \\ EUR] in our book store. \\ Screen A: Patterns of books purchases \\ A1. Many books are now available in electronic formats. Over the past three months, how many books have you.... \\ ... read as an ebook

$$
\text { none } \quad 1-3 \text { books } \quad 4-6 \text { books } \quad 7-12 \text { books } \quad 13+\text { books }
$$ \\ .. read as a traditional book \\ A2. And over the past three months, how many books have you....

\begin{tabular}{|c|c|c|c|c|}
\hline \multicolumn{5}{|c|}{ 3. How do you acquire your books? Select all that apply } \\
\hline a) buy in a traditional bookstore & b) & buy in an electronic bookstore & c) & borrow from the library \\
\hline borrow from family/friends & e) & receive as a gift & f) & find free books on the net \\
\hline find on file-sharing services & h) & exchange files with family/friends & i) & buy in online auctions \\
\hline \multicolumn{5}{|c|}{ 4. Which is the most frequent method for you? Select only one. } \\
\hline a) buy in a traditional bookstore & & buy in an electronic bookstore & c) & borrow from the library \\
\hline $\begin{array}{l}\text { d) borrow from family/friends } \\
\text { g) find on file-sharing services }\end{array}$ & & $\begin{array}{l}\text { receive as gifts } \\
\text { exchange files with family/friends }\end{array}$ & $\begin{array}{l}\text { f) } \\
\text { i) }\end{array}$ & $\begin{array}{l}\text { find free books on the net } \\
\text { buy in online auctions }\end{array}$ \\
\hline
\end{tabular} \\ h) exchange files with family/friends
}

A5. How important are the following matters to you?

a) The authors receive their share of sales proceeds

Not important Somewhat important Very important

b) The distribution of the book is fully legitimate

c) The book may be lent or given to someone

d) The looks of the book

e) Physical size or weight of the book

f) Purchasing is convenient

g) Price

h) Transaction cost (postage, getting to the store, etc)

i) Delivery time

Screen B: Randomization between Bayesian Truth Serum condition and Control condition

[Bayesian Truth Serum condition] Like in many other studies, we are very concerned about truthful answers. In questions below we rely on a method proposed by Drazen Prelec, a psychologist from Harvard, published in the prestigious journal "Science". This method gives more point to those who:

- answer truthfully

- accurately predict the answers of the other participants of the survey.

The more points you acquire, the greater is your chance of winning the coupon.

[Control condition: no additional message]

B1. Over the past three months, have you acquired an audiobook or an ebook from an unauthorized internet source? By an unauthorized internet source we mean platforms such as Chomikuj.pl, peer-to-peer networks such as BitTorrent and others, where users may share the files with all other Internet users.

B2. In your opinion, what percentage of Publio clients answered "yes" to this question?
$<10 \%$
$11-20 \%$
$21-30 \%$
$31-40 \%$
$41-50 \%$
$51-60 \%$
$61-70 \%$
$71-80 \% \quad 81-90 \% \quad 91-100 \%$

B3. In your opinion, what percentage of people who actually acquired an audiobook or an ebook from an unauthorized internet source answered "yes" to this question?

$<10 \% \quad 11-20 \% \quad 21-30 \% \quad 31-40 \% \quad 41-50 \% \quad 51-60 \% \quad 61-70 \% \quad 71-80 \% \quad 81-90 \% \quad 91-100 \%$

Screen C: Reasons for acquiring books from unauthorized sources and price fairness

C1. When people acquire content from unauthorized sources, why do you think they do so? (Please mark up to three answers.)

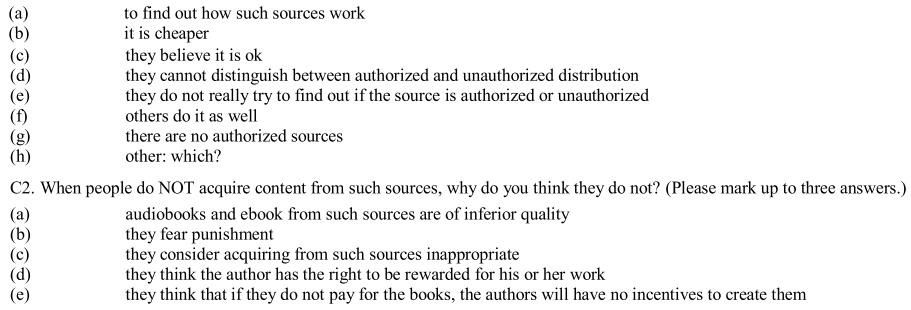




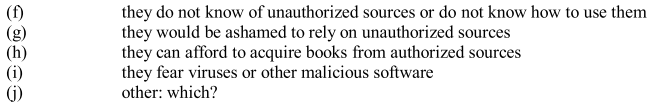

C3. Research shows that many people making use of unauthorized sources do not admit to doing so. Why do you think they don't? (Please mark all the relevant answers)

(a) because they are afraid of punishment associated with using such sources

(b) because they find using such sources embarrassing

(c) because they think that using such sources is inappropriate or wrong

(d) other: which?

The four questions below concern the last fiction book that you have bought (regardless of its format; ebook, audiobook, paper)

C4. How much did the last fiction book that you have bought cost?

C5. What is the maximum price you would be willing to pay for this particular book?

C6. What price for this particular book would you consider fair?

C7. If that book was available for sale in a 'pay-what-you-want scheme', how much would you have paid for it'?

Screen D: Opinions on unauthorized sources

D1. What do you think about file-hosting platforms like Chomikuj.pl or peer-to-peer networks such as BitTorrent, where people may share files with all the internet users?

A. If services like these exist, they cannot be illegal

B. Placing limitations on how people can share books with strangers constrain personal freedom

C. There is nothing inappropriate about downloading books that cannot be

purchased otherwise
D. Services such as those are an equivalent of public libraries

E. Unclear or incorrect laws, such as the regulation on file-sharing through such services, may be ignored

F. Books are cultural goods, there is nothing inappropriate about making them available to everyone.

G. Electronic books do not have the same value as paper books, so the services such as those should not raise concerns.

$\mathrm{H}$. There is no reason for paying the publishers, if books may be acquired for free from such services.

I. Services as those are used by people who cannot afford buying expensive books

J. There is no harm from services like those, because those who use it, would not

buy books anyway.

$\mathrm{K}$. Services such as those earn profits at the expense of authors and publishers.

L. Distributing copyrighted content through services such as these is theft and those services are equally responsible for this crime

$M$. Services such as these will eventually reduce the influx of new books,

because publishers will not be able to pay the authors.

Screen E: Confidential questions by Publio.

Screen F: Socio-demographic questions

Age, gender, education (incomplete primary, primary, vocational, secondary, tertiary), size of household, residence (above 500000 inhabitants, between 100000 and 500000 inhabitants, less than 100000 inhabitants but within a metropolitan area, less than 100000 inhabitants and not in a metropolitan area), how would you characterize the income status of your household (we can afford luxury, we can afford expenses without much saving effort, we can afford daily expenses but larger expenses require saving, we have to be cautious about daily expenses, we cannot afford daily expenses).

Screen G: More questions by Publio.

\section{References}

Adams, J. S. (1963). Towards an understanding of inequity. Journal of Abnormal and Social Psychology, 67(5), 422-436

Al-Rafee, S., \& Cronan, T. P. (2006). Digital piracy: Factors that influence attitude toward behavior. Journal of Business Ethics, 63(3), 237-259. 
Balan, C. (2014). Pay what you want: A participative price setting mechanism. International Journal of Economic Practices and Theories, 4(5), 952-963.

Barrage, L., \& Lee, M. S. (2010). A penny for your thoughts: Inducing truth-telling in stated preference elicitation. Economics Letters, 106(2), 140-142.

Blanken, I., van de Ven, N., \& Zeelenberg, M. (2015). A meta-analytic review of moral licensing. Personality and Social Psychology Bulletin, 41(4), 540-558.

Bougie, R., Pieters, R., \& Zeelenberg, M. (2003). Angry customers don't come back, they get back: The experience and behavioral implications of anger and dissatisfaction in services. Journal of the Academy of Marketing Science, 31(4), 377-393.

Brehm, S. S., \& Brehm, J. W. (1981). Psychological reactance: A theory of freedom and control. Cambridge: Academic Press.

Brehm, S. S., \& Brehm, J. W. (2003). Psychological reactance: A theory of freedom and control. Academic Press.

Campbell, M. C. (1999). Perceptions of price unfairness: Antecedents and consequences. Journal of Marketing Research, 36(2), 187-199.

Carlsmith, J. M., \& Gross, A. E. (1969). Some effects of guilt on compliance. Journal of Personality and Social Psychology, 11(3), 232-240.

Darke, P. R., \& Dahl, D. W. (2003). Fairness and discounts: The subjective value of a bargain. Journal of Consumer Psychology, 13(3), 328-338.

Filiciak, M., Hofmokl, J., Jaosiska, A. \& Tarkowski, A. (2012). The circulations of culture: On social distribution of content. Centrum Cyfrowe Projekt: Polska. http://obiegikultury.centrumcyfrowe.pl.

Gneezy, A., Gneezy, U., Riener, G., \& Nelson, L. D. (2012). Pay-what-you-want, identity, and self-signaling in markets. Proceedings of the National Academy of Sciences, 109(19), 7236-7240.

Gupta, P. B., Gould, S. J., \& Pola, B. (2004). To pirate or not to pirate: A comparative study of the ethical versus other influences on the consumers software acquisition-mode decision. Journal of Business Ethics, 55(3), 255-274.

Hardy, W., Krawczyk, M. \& Tyrowicz, J. (2018). Friends or foes? A meta-analysis of the link between "online piracy" and sales of cultural goods. Working Paper-Faculty of Economic Sciences, University of Warsaw, WP23/171.

Higgins, G. E., Wolfe, S. E., \& Ricketts, M. L. (2008). Digital piracy: A latent class analysis. Social Science Computer Review, 27(1), 24-40.

Hill, C. W. L. (2007). Digital piracy: Causes, consequences, and strategic responses. Asia Pacific Journal of Management, 24(1), 9-25.

Hinduja, S. (2003). Trends and patterns among online software pirates. Ethics and Information Technology, 5(1), 49-61.

Homburg, C., Koschate, N., \& Hoyer, W. D. (2005). Do satisfied customers really pay more? A study of the relationship between customer satisfaction and willingness to pay. Journal of Marketing, 69(2), 84-96.

Howie, P. J., Wang, Y., \& Tsai, J. (2011). Predicting new product adoption using Bayesian Truth Serum. Journal of Medical Marketing: Device, Diagnostic and Pharmaceutical Marketing, 11(1), 6-16.

Huppertz, J. W., Arenson, S. J., \& Evans, R. H. (1978). An application of equity theory to buyer-seller exchange situations. Journal of Marketing Research, 15(2), 250-260.

John, L. K., Loewenstein, G., \& Prelec, D. (2012). Measuring the prevalence of questionable research practices with incentives for truth telling. Psychological Science, 23(5), 524-532.

Kahneman, D., Knetsch, J. L., \& Thaler, R. (1986). Fairness as a constraint on profit seeking: Entitlements in the market. The American Economic Review, 1986, 728-741.

Kim, J.-Y., Natter, M., \& Spann, M. (2009). Pay what you want: A new participative pricing mechanism. Journal of Marketing, 73(1), 44-58.

Korys, I., Michalak, D. \& Chymkowski, R. (2015). Stan czytelnictwa w Polsce w 2014 roku. Biblioteka Narodowa. http://www.bn.org.pl/aktualnosci/835-raport.

Kwong, K. K., Yau, O. H. M., Lee, J. S. Y., Sin, L. Y. M., \& Tse, A. C. B. (2003). The effects of attitudinal and demographic factors on intention to buy pirated CDs: The case of Chinese consumers. Journal of Business Ethics, 47(3), 223-235.

Liebowitz, S. J. (2016). How much of the decline in sound recording sales is due to file-sharing? Journal of Cultural Economics, 40(1), 13-28.

Lysonski, S., \& Durvasula, S. (2008). Digital piracy of MP3s: Consumer and ethical predispositions. Journal of Consumer Marketing, 25(3), 167-178. 
Miyazaki, A. D., Rodriguez, A. A., \& Langenderfer, J. (2009). Price, scarcity, and consumer willingness to purchase pirated media products. Journal of Public Policy and Marketing, 28(1), 71-84.

Nunes, J. C., Hsee, C. K., \& Weber, E. U. (2004). Why are people so prone to steal software? The effect of cost structure on consumer purchase and payment intentions. Journal of Public Policy and Marketing, 23(1), 43-53.

Phau, I., Lim, A., Liang, J., \& Lwin, M. (2014). Engaging in digital piracy of movies: A theory of planned behaviour approach. Internet Research, 24(2), 246-266.

Prelec, D. (2004). A Bayesian truth serum for subjective data. Science, 306(5695), 462-466.

Ross, L., Greene, D., \& House, P. (1977). The false consensus effect: An egocentric bias in social perception and attribution processes. Journal of Experimental Social Psychology, 13(3), 279-301.

Shaw, A. D., Horton, J. J. \& Chen, D. L. (2011). Designing incentives for inexpert human raters. In Proceedings of the ACM 2011 conference on computer supported cooperative work (pp. 275-284). ACM.

Sonnabend, H. (2016). Fairness constraints on profit-seeking: Evidence from the German club concert industry. Journal of Cultural Economics, 40(4), 529-545.

Tan, B. (2002). Understanding consumer ethical decision making with respect to purchase of pirated software. Journal of Consumer Marketing, 19(2), 96-111.

Tetlock, P. E., Kristel, O. V., Elson, S. B., Green, M. C., \& Lerner, J. S. (2000). The psychology of the unthinkable: Taboo trade-offs, forbidden base rates, and heretical counter factuals. Journal of Personality and Social Psychology, 78(5), 853-862.

Thaler, R. (1985). Mental accounting and consumer choice. Marketing Science, 4(3), 199-214.

Voelckner, F. (2006). An empirical comparison of methods for measuring consumers' willingness to pay. Marketing Letters, 17(2), 137-149.

Weaver, R., \& Prelec, D. (2013). Creating truth-telling incentives with the Bayesian Truth Serum. Journal of Marketing Research, 50(3), 289-302.

Weiss, R. J. (2009). Optimally aggregating elicited expertise: A proposed application of the Bayesian Truth Serum for policy analysis. Ph.D. thesis, Massachusetts Institute of Technology.

West, C., \& Zhong, C. B. (2015). Moral cleansing. Current Opinion in Psychology, 6, 221-225.

Xia, L., Monroe, K. B., \& Cox, J. L. (2004). The price is unfair! A conceptual framework of price fairness perceptions. Journal of Marketing, 68(4), 1-15.

Zeelenberg, M., \& Pieters, R. (2004). Beyond valence in customer dissatisfaction: A review and new findings on behavioral responses to regret and disappointment in failed services. Journal of Business Research, 57(4), 445-455.

Publisher's Note Springer Nature remains neutral with regard to jurisdictional claims in published maps and institutional affiliations. 